\title{
Assessment of the implementation of DOTS strategy in two chest facilities in Alexandria, Egypt
}

A.A. Elmahalli ${ }^{1}$ and B.F. Abdel-Aziz ${ }^{1}$

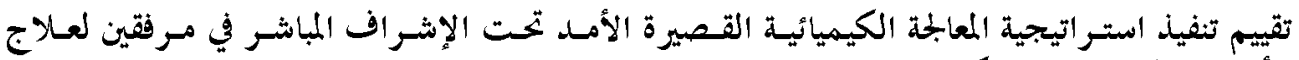

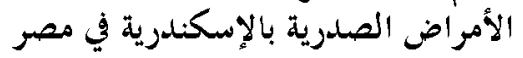

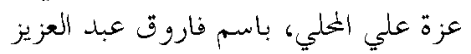

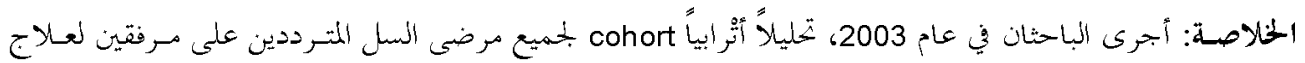

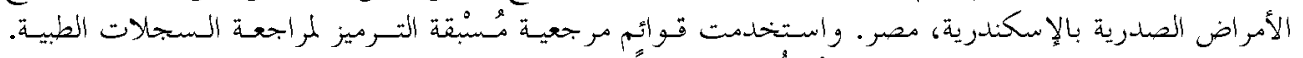

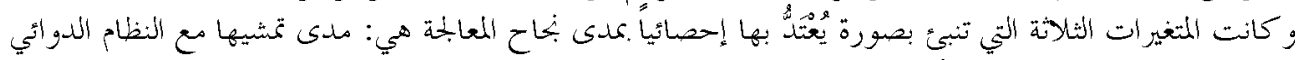

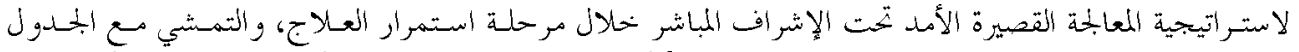

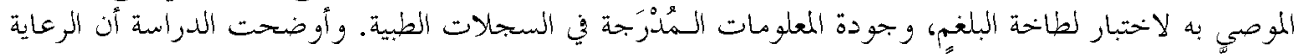

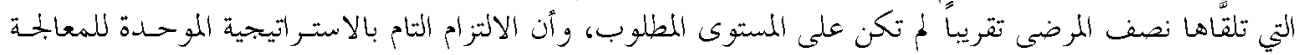

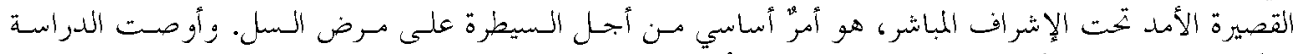

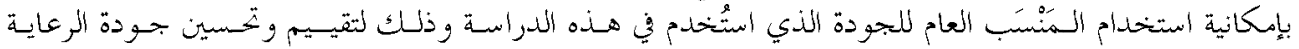

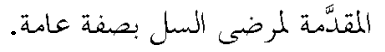

ABSTRACT We conducted a cohort analysis of all patients with tuberculosis (TB) attending 2 chest facilities in Alexandria, Egypt for the year 2003. A pre-coded checklist was used for auditing medical records. Conformity to the DOTS drug regimen during the continuation phase of therapy, conformity to the recommended schedule of sputum smear microscopy, and quality of registration of medical records were the 3 variables that significantly predicted treatment success. About half the patients received poor quality care. Strict adherence to standardized DOTS strategy is essential to bring TB under control. The overall quality index devised in this study may be used to assess and improve overall quality of antituberculosis care.

\begin{abstract}
Évaluation de l'application de la stratégie DOTS dans deux services de pneumologie d'Alexandrie en Égypte

RÉSUMÉ Nous avons mené une étude de cohorte portant sur l'ensemble de la population de patients tuberculeux accueillis au cours de l'année 2003 dans deux services de pneumologie d'Alexandrie en Égypte. Les dossiers médicaux ont été vérifiés sur la base d'une liste précodée. L'observance du schéma thérapeutique DOTS [pour Directly Observed Treatment, Short-course - traitement de brève durée sous surveillance directe], le respect du calendrier des examens microscopiques de frottis d'expectoration recommandé et la qualité de la tenue des dossiers médicaux se sont avérés être les 3 prédicteurs de succès thérapeutique les plus significatifs. Les soins reçus par près de la moitié des patients étaient de qualité médiocre. La lutte contre la tuberculose exige l'adhésion la plus étroite à la stratégie DOTS. L'indice global de qualité élaboré pour les besoins de cette étude peut être utilisé pour évaluer et améliorer la qualité globale de la prise en charge de la tuberculose.
\end{abstract}

${ }^{1}$ Department of Health Administration and Planning, High Institute of Public Health, Alexandria University, Alexandria, Egypt (Correspondence to B.F. Abdel-Aziz: basemfarouk@yahoo.com).

Received: 07/04/05; accepted: 03/10/05 


\section{Introduction}

Tuberculosis (TB) is re-emerging as a world problem: it kills more people than any other infectious disease, being the direct cause of death of more than 2 million people annually [1-3]. Paradoxically TB is preventable and curable $[1,4]$. In Egypt it is estimated that approximately 16 new cases appear annually per 100000 population. Verticallyoriented control programmes have failed [5].

In 1989 a new framework for effective TB control was created and branded DOTS, the acronym standing for "directly observed treatment, short-course" chemotherapy [0]. DOTS is a standardized protocol for diagnosis, treatment and monitoring that ensures the political and administrative support required for effective control of TB [7]. The strategy provides a framework for effective TB control comprising 5 essential elements. Two elements are technical: case finding through bacteriological examination of patients with respiratory symptoms attending primary health care units and administration of short-course chemotherapy, mostly by direct observation. The other 3 elements are managerial: generating greater political commitment to mobilize sufficient resources for TB control, securing a regular supply of antituberculosis drugs, and establishing a reliable information system to provide data for monitoring and assessing case-finding and treatment activities [8].

This strategy was adopted in Egypt aiming at detection of $\geq 70 \%$ of existing infectious cases and a cure rate of $\geq 85 \%$ of detected cases [5]. A hallmark of this strategy is that every dose of antituberculosis drugs is administered under direct observation to ensure patients' adherence, follow-up and early management of complications [9]. The cost-effectiveness of this approach has been demonstrated in several studies [10,11]. Moreover, TB patients have an excellent chance of being cured, as shorttreatment regimens can achieve $>95 \%$ cure, as documented in Benin, Cambodia, Chile, China, Malawi, Morocco, Nicaragua, Peru, Tanzania, Uruguay and Vietnam [12-20]. In other developing countries, however, initial success in the control of TB led to complacency, a subsequent resurgence of cases and the emergence and spread of resistant strains [21-23].

In a DOTS-directed programme, records are used systematically to evaluate patients' progress, treatment outcome and programme performance as well as to identify problems that need to be solved [24-26]. Recently, TB research, from the most basic to the more operational research on health policy and systems, has attracted new interest at the World Health Organization (WHO) and in many public health and academic institutions. Thus, TB is coming back vigorously onto the public health agenda, both locally and globally $[27,28]$.

The basic principle of TB control is that the health system, not the patient, is responsible and accountable for ensuring proper quality of care [29]. In developing countries, health care delivery systems have been criticized for not being able to produce tangible results and the credibility of such systems would increase substantially if concrete results in terms of health service outputs could be demonstrated. It is argued that the indicators used for monitoring TB control programmes can be used as excellent tools for monitoring process and outcome of antituberculosis care. This is especially true in developing countries, where TB is a major public health problem [30]. Therefore, assessment of the implementation of DOTS strategy for TB management cannot be underestimated.

The aim of this study was to assess the implementation of DOTS strategy at 2 
governmental chest facilities in Alexandria, Egypt.

Study objectives included:

- assessing the quality of process and outcome of care delivered to TB patients at the study settings according to DOTS strategy;

- appraising adherence to elements of DOTS strategy, including smear microscopy, drug regimen, and medical record keeping according to DOTS strategy;

- assessing a hypothesized relationship between process and outcome of antituberculosis care according to DOTS strategy.

\section{Methods}

Records of patients who attended chest facilities in El-Mamora and Bacos, Alexandria, Egypt for TB treatment between 1 January 2003 and 31 December 2003 were audited, irrespective of age, sex or TB type. These settings were selected as they represented the highest utilization counts during the period 2000-2004. Total number of medical records examined was 249.

Data were collected through a pre-coded checklist, covering items pertaining to patients' personal data and data related to process and outcome of care. A total of 20 items were audited. Quality of performance was appraised via an overall quality index composed of 5 parameters: quality of registration in medical records; adherence to recommended schedule of sputum smear microscopy according to DOTS strategy; conformity to drug regimen during the initial phase of therapy according to DOTS strategy; conformity to drug regimen during the continuation phase; and success of treatment. Quality of registering medical records was assessed by assigning a score of 1 for recorded items and 0 for unrecorded items. Maximum attainable score was 20 and minimum score for a record was 0 . Percentage score for each record was calculated and quality of medical recording was classified as: very poor $(0 \%-<50 \%)$, poor $(50 \%-<60 \%)$, marginal $(60 \%-$ $<70 \%)$, good $(70 \%-<80 \%)$, very good $(80 \%-<90 \%)$ and excellent $(90 \%-100 \%)$.

Adherence to the recommended schedule of sputum smear microscopy was assessed using the WHO recommended schedule of sputum smear microscopy according to DOTS strategy as a yardstick [5].

An index for smear microscopy compliance was devised comprising 2 elements, number of smears performed and timeliness in performing the smears. Accordingly, a case in which the required number of smears (usually 4) were fulfilled was accorded a score of 1, i.e. a complete score for the first element; however, if $\geq 1$ smears were missing, the appropriate fraction was subtracted from the score, e.g. if the recommended treatment regimen prescribed 4 smears but only 3 smears were performed, then the score attained for that element was $1.00-0.25=0.75$. If the treatment regimen prescribed 5 smears, however, and only 4 were performed, this was accorded a score of $1.00-0.20=0.8$.

If the required smears were accomplished on time, a score of 1 was assigned, i.e. a complete score for the second element. If a smear was delayed, its fraction contributing to the overall score was 0 since only a timely smear was assigned a full score.

To attain an overall score (index) for smear microscopy adherence to the recommended schedule, the scores of the 2 elements (for a given case) were multiplied. Quality of smear performance microscopy was classified as: very poor $(0-<0.5)$, poor $(0.5-<0.6)$, marginal $(0.6-<0.7)$, good $(0.7-<0.8)$, very good $(0.8-<0.9)$ and excellent (0.9-1). Conformity to drug regimen 
according to DOTS strategy was used as a yardstick [31].

Cases were classified as adhering or nonadhering to the recommended drug regimen (type, number and duration); adhering cases were assigned a score of 1 and non-adhering cases a score of 0 . Success rate was calculated as per cent cured + per cent completed treatment $[7,32]$. Patients were categorized as successful or unsuccessful $(1,0)$ for the purposes of logistic regression analysis.

The overall quality index used in the present study was a composite index devised to evaluate the quality of antituberculosis care. This index was computed by multiplying 5 parameters: quality of record registration; sputum smear microscopy adherence index; drug regimen conformity index during the initial phase; drug regimen conformity index during the continuation phase; and outcome of care. Overall quality was graded as: poor $(0-<0.5)$, good $(0.5-<0.9)$ and excellent $(0.9-1)$.

Data were analysed using mean, standard deviation and percentage. Univariate analyses (chi-squared test and Pearson's correlation) were used to detect significant associations between treatment success and other important study variables such as sex, age, employment status, diagnostic category, facility, index of conformity to the WHO-recommended schedule for smear microscopy, conformity to WHO-recommended drug regimen during initial and continuation phases of therapy, and index of quality of registration of patients' medical records.

All variables found to be significantly associated with treatment success (dependent variable) were included as independent variables in a logistic regression analysis (backward stepwise Wald). Analysis was performed at $95 \%$ and $99 \%$ confidence intervals. Data were analysed using SPSS, version 12 , and charts were constructed using Excel 5, 2003.

\section{Results}

The majority of patients, $82.4 \%$, were in the age group $15-<60$ years (Table 1). Most were males, $70.7 \%$ of the total. Employment status of patients differed in the 2 facilities, $36.8 \%$ in El-Mamora were unemployed and $80.5 \%$ in Bacos. Regarding diagnosis, the highest frequency at both facilities was for new smear-positive pulmonary TB cases $(53.7 \%$ at El-Mamora and $47.9 \%$ at Bacos), i.e. just over half the total number of cases. With respect to treatment outcome, overall $48.6 \%$ were cured cases and $40.6 \%$ completed treatment; defaulters constituted only $2.0 \%$.

Most of the process items were always registered on the TB treatment card (Table 2). However, neither BCG scar examination nor drug and susceptibility testing were registered at either facility. Registration of sputum smear microscopy declined from the 1st smear, 92.6\% for El-Mamora and $86.8 \%$ for Bacos, to $81.6 \%$ for El-Mamora and $59.3 \%$ for Bacos for the 4th smear.

Quality of registration was evaluated as good overall. Specifically, quality of registration was very good at El-Mamora and good at Bacos.

The proper number of smears was performed in $39.0 \%$ of cases overall (Table 3 ). Smears were performed on time for $97.8 \%$ of cases in El-Mamora but only $73.5 \%$ in Bacos $(86.7 \%$ overall).

In the course of therapy, $86.6 \%(110 / 127)$ of the cases converted to negative status as verified by the second smear. By the third smear only $5.5 \%(7 / 127)$ continued to be smear-positive.

The type and number of drugs conformed to DOTS recommendations in $85.5 \%$ of cases during the initial phase and $94.8 \%$ of cases during the continuation phase (Table 4). The duration of antituberculosis therapy was complete for $84.7 \%$ of cases during the 


\begin{tabular}{|c|c|c|c|c|c|c|}
\hline \multirow[t]{2}{*}{ Characteristic } & \multicolumn{2}{|c|}{$\begin{array}{c}\text { El-Mamora } \\
(n=136)\end{array}$} & \multicolumn{2}{|c|}{$\begin{array}{c}\text { Bacos } \\
(n=113)\end{array}$} & \multicolumn{2}{|c|}{$\begin{array}{c}\text { Total } \\
(n=249)\end{array}$} \\
\hline & No. & $\%$ & No. & $\%$ & No. & $\%$ \\
\hline \multicolumn{7}{|l|}{ Age (years) } \\
\hline $0-$ & 7 & 5.1 & 4 & 3.5 & 11 & 4.4 \\
\hline 15- & 115 & 84.6 & 90 & 79.7 & 205 & 82.4 \\
\hline $60+$ & 14 & 10.3 & 17 & 15.0 & 31 & 12.4 \\
\hline Unrecorded & - & - & 2 & 1.8 & 2 & 0.8 \\
\hline Mean (SD) & \multicolumn{2}{|c|}{$36.7(16.0)$} & \multicolumn{2}{|c|}{$38.8(17.3)$} & \multicolumn{2}{|c|}{$37.6(16.6)$} \\
\hline \multicolumn{7}{|l|}{ Sex } \\
\hline Male & 100 & 73.5 & 76 & 67.3 & 176 & 70.7 \\
\hline Female & 36 & 26.5 & 37 & 32.7 & 73 & 29.3 \\
\hline \multicolumn{7}{|l|}{ Employment status } \\
\hline Unemployed & 50 & 36.8 & 91 & 80.5 & 141 & 56.6 \\
\hline Employed & 80 & 58.8 & 20 & 17.7 & 100 & 40.2 \\
\hline Child & 6 & 4.4 & 2 & 1.8 & 8 & 3.2 \\
\hline \multicolumn{7}{|l|}{ Diagnostic category } \\
\hline New, smear +ve pulmonary TB (I) & 73 & 53.7 & 54 & 47.9 & 127 & 51.0 \\
\hline $\begin{array}{l}\text { Relapsing smear +ve } \\
\text { pulmonary TB (II) }\end{array}$ & 2 & 1.5 & 5 & 4.4 & 7 & 28 \\
\hline Treatment failure, smear +ve & & & & & & \\
\hline pulmonary TB (II) & 2 & 1.5 & 8 & 7.0 & 10 & 4.0 \\
\hline New, severe form of smear -ve TB (I) & 3 & 2.2 & 2 & 1.8 & 5 & 2.0 \\
\hline New, smear -ve pulmonary TB (III) & 28 & 20.6 & 20 & 17.7 & 48 & 19.3 \\
\hline $\begin{array}{l}\text { New, less-severe form of } \\
\text { extrapulmonary TB (III) }\end{array}$ & 24 & 17.7 & 16 & 14.2 & 40 & 16.1 \\
\hline New, severe form of & & & & & & \\
\hline extrapulmonary TB (I) & 2 & 1.5 & 4 & 3.5 & 6 & 2.4 \\
\hline Unrecorded cases & 2 & 1.5 & 4 & 3.5 & 6 & 2.4 \\
\hline \multicolumn{7}{|l|}{ Diagnostic category } \\
\hline I & 78 & 57.4 & 60 & 53.1 & 138 & 55.5 \\
\hline II & 4 & 2.9 & 13 & 11.5 & 17 & 6.8 \\
\hline III & 52 & 38.2 & 36 & 31.9 & 88 & 35.3 \\
\hline IV & 0 & - & 0 & - & 0 & - \\
\hline Unrecorded cases & 2 & 1.5 & 4 & 3.5 & 6 & 2.4 \\
\hline \multicolumn{7}{|l|}{ Treatment outcome } \\
\hline Cured & 70 & 51.5 & 51 & 45.1 & 121 & 48.6 \\
\hline Completed treatment & 53 & 39.0 & 48 & 42.5 & 101 & 40.6 \\
\hline Treatment failure & 3 & 2.2 & 6 & 5.3 & 9 & 3.6 \\
\hline Default & 4 & 2.9 & 1 & 0.9 & 5 & 2.0 \\
\hline Death & 0 & - & 4 & 3.5 & 4 & 1.6 \\
\hline Transfer out & 6 & 4.4 & 3 & 2.7 & 9 & 3.6 \\
\hline
\end{tabular}

Overall success rate (cured cases + those completed treatment) $=48.6 \%+40.6 \%=89.2 \%$. $S D=$ standard deviation 


\begin{tabular}{|c|c|c|c|c|c|c|}
\hline \multirow[t]{2}{*}{ Item } & \multicolumn{2}{|c|}{$\begin{array}{c}\text { El-Mamora } \\
(n=136)\end{array}$} & \multicolumn{2}{|c|}{$\begin{array}{c}\text { Bacos } \\
(n=113)\end{array}$} & \multicolumn{2}{|c|}{$\begin{array}{c}\text { Total } \\
(n=249)\end{array}$} \\
\hline & No. & $\%$ & No. & $\%$ & No. & $\%$ \\
\hline Name & 136 & 100.0 & 113 & 100.0 & 249 & 100.0 \\
\hline Age & 136 & 100.0 & 111 & 98.8 & 247 & 99.2 \\
\hline Occupation & 136 & 100.0 & 113 & 100.0 & 249 & 100.0 \\
\hline Sex & 136 & 100.0 & 113 & 100.0 & 249 & 100.0 \\
\hline Address & 136 & 100.0 & 113 & 100.0 & 249 & 100.0 \\
\hline TB registry & 136 & 100.0 & 113 & 100.0 & 249 & 100.0 \\
\hline Weight & 136 & 100.0 & 109 & 96.5 & 240 & 96.4 \\
\hline Start date of initial phase & 136 & 100.0 & 106 & 93.8 & 242 & 97.2 \\
\hline Place of therapy & 136 & 100.0 & 83 & 73.5 & 219 & 88.0 \\
\hline BCG scar examination & 0 & - & 0 & - & 0 & - \\
\hline First sputum smear microscopy & 126 & 92.6 & 98 & 86.8 & 224 & 90.0 \\
\hline Second sputum smear microscopy & 116 & 85.3 & 72 & 63.7 & 188 & 75.5 \\
\hline Third sputum smear microscopy & 110 & 80.9 & 70 & 62.0 & 180 & 72.3 \\
\hline Fourth sputum smear microscopy & 111 & 81.6 & 67 & 59.3 & 178 & 71.5 \\
\hline Fifth sputum smear microscopy & 12 & 8.8 & 14 & 12.4 & 26 & 10.4 \\
\hline Drug and susceptibility testing & 0 & - & 0 & - & 0 & - \\
\hline Diagnosis & 134 & 98.5 & 109 & 96.5 & 243 & 97.6 \\
\hline Drugs administered in initial phase & 135 & 99.3 & 10 & 96.5 & 244 & 98.0 \\
\hline Drugs prescribed in continuation phase & 133 & 97.8 & 108 & 95.6 & 241 & 96.8 \\
\hline Treatment outcome & 136 & 100.0 & 113 & 100.0 & 249 & 100.0 \\
\hline Raw quality score [mean (SD)] & 82. & $(16.5)$ & 76. & $(15.4)$ & 79.6 & $(15.9)$ \\
\hline Quality level & Ver & good & & ood & & ood \\
\hline
\end{tabular}

$S D=$ standard deviation.

initial phase and $89.6 \%$ during the continuation phase. Treatment regimen conformed to DOTS requirements in $74.7 \%$ of cases during the initial phase and $87.5 \%$ during the continuation phase.

Quality of care was graded as poor for $79.2 \%$ of cases at Bacos, compared to $24.3 \%$ of cases at El-Mamora. In total, $49.8 \%$ of cases received poor quality care.

Treatment success was significantly correlated to the indices of conformity to the smear microscopy schedule and quality of registration of medical records (Table 5).

Treatment success was statistically significantly correlated $(P<0.001)$ with diagnostic category and conformity to drug regimen during the continuation phase of therapy (Table 6).

Table 7 shows a logistic regression model with treatment success as the dependent variable and variables significantly related to it as shown in univariate analysis as in- 
Table 3 Compliance with performing required smear microscopy according to DOTS strategy at two chest facilities in Alexandria

\begin{tabular}{|c|c|c|c|c|c|c|}
\hline \multirow[t]{2}{*}{ Smear microscopy } & \multicolumn{2}{|c|}{$\begin{array}{c}\text { El-Mamora } \\
(n=136)\end{array}$} & \multicolumn{2}{|c|}{$\begin{array}{c}\text { Bacos } \\
(n=113)\end{array}$} & \multicolumn{2}{|c|}{$\begin{array}{c}\text { Total } \\
(n=249)\end{array}$} \\
\hline & No. & $\%$ & No. & $\%$ & No. & $\%$ \\
\hline \multicolumn{7}{|l|}{ No. of smears done } \\
\hline Proper no. & 55 & 40.4 & 42 & 37.2 & 97 & 39.0 \\
\hline 1 smear omitted & 21 & 15.4 & 17 & 15.0 & 38 & 15.3 \\
\hline 2 smears omitted & 6 & 4.4 & 17 & 15.0 & 23 & 9.2 \\
\hline$\geq 3$ smears omitted & 17 & 12.5 & 14 & 12.4 & 31 & 12.4 \\
\hline Surplus of 1 smear & 37 & 27.2 & 19 & 16.8 & 56 & 22.5 \\
\hline Not applicable (death) & 0 & - & 4 & 3.5 & 4 & 1.6 \\
\hline \multicolumn{7}{|l|}{ Timeliness of smears } \\
\hline On time & 133 & 97.8 & 83 & 73.5 & 216 & 86.7 \\
\hline 2 months late & 1 & 0.7 & 12 & 10.6 & 13 & 5.2 \\
\hline 3 months late & 2 & 1.5 & 7 & 6.2 & 9 & 3.6 \\
\hline 4 months late & 0 & - & 7 & 6.2 & 7 & 2.8 \\
\hline \multirow[t]{2}{*}{ Not applicable (death) } & 0 & - & 4 & 3.5 & 4 & 1.6 \\
\hline & \multicolumn{2}{|c|}{$\begin{array}{l}\text { Mean score } \\
\text { (SD) }\end{array}$} & \multicolumn{2}{|c|}{$\begin{array}{l}\text { Mean score } \\
\text { (SD) }\end{array}$} & \multicolumn{2}{|c|}{$\begin{array}{c}\text { Mean score } \\
\text { (SD) }\end{array}$} \\
\hline \multicolumn{7}{|c|}{ Quality of smear microscopy } \\
\hline No. of smears & \multicolumn{2}{|c|}{$0.83(0.30)$} & \multicolumn{2}{|c|}{$0.76(0.33)$} & \multicolumn{2}{|c|}{$0.80(0.31)$} \\
\hline Timeliness of smear & \multicolumn{2}{|c|}{$0.99(0.09)$} & \multicolumn{2}{|c|}{$0.83(0.32)$} & \multicolumn{2}{|c|}{$0.92(0.24)$} \\
\hline Overall quality & \multicolumn{2}{|c|}{$0.82(0.31)$} & \multicolumn{2}{|c|}{$0.63(0.37)$} & \multicolumn{2}{|c|}{$0.74(0.35)$} \\
\hline Grading & \multicolumn{2}{|c|}{ Very good } & \multicolumn{2}{|c|}{ Marginal } & \multicolumn{2}{|c|}{ Good } \\
\hline
\end{tabular}

\begin{tabular}{|c|c|c|c|c|c|c|}
\hline \multirow[t]{2}{*}{ Drug regimen } & \multicolumn{3}{|c|}{ Initial phase of therapy } & \multicolumn{3}{|c|}{ Continuation phase of therapy } \\
\hline & $\begin{array}{c}\text { El-Mamora } \\
(n=136) \\
\%\end{array}$ & $\begin{array}{c}\text { Bacos } \\
(n=113) \\
\%\end{array}$ & $\begin{array}{c}\text { Total } \\
(n=249) \\
\%\end{array}$ & $\begin{array}{c}\text { EI-Mamora } \\
(n=136) \\
\%\end{array}$ & $\begin{array}{c}\text { Bacos } \\
(n=113) \\
\%\end{array}$ & $\begin{array}{c}\text { Total } \\
(n=249) \\
\%\end{array}$ \\
\hline $\begin{array}{l}\text { Type \& no. of prescribed } \\
\text { drugs conforming to } \\
\text { DOTS }\end{array}$ & 89.0 & 81.4 & 85.5 & 96.3 & 92.9 & 94.8 \\
\hline $\begin{array}{l}\text { Duration of therapy } \\
\text { complete }\end{array}$ & 100.0 & 66.4 & 84.7 & 97.8 & 79.6 & 89.6 \\
\hline $\begin{array}{l}\text { Regimen conforming to } \\
\text { DOTS }\end{array}$ & 89.0 & 57.5 & 74.7 & 94.9 & 78.8 & 87.5 \\
\hline $\begin{array}{l}\text { Mean no. of drugs/patient } \\
\text { (SD) }\end{array}$ & t $3.6(0.98)$ & $3.7(0.98)$ & $3.6(0.85)$ & $2.1(0.51)$ & $2.1(0.75)$ & $2.1(0.63)$ \\
\hline
\end{tabular}




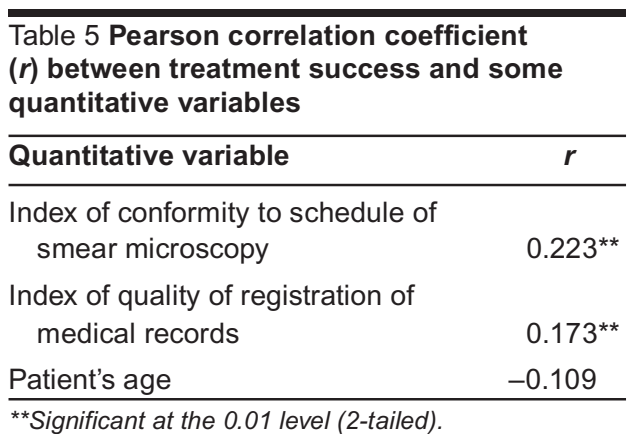

dependent variables. Conformity to DOTS drug regimen during the continuation phase of therapy, conformity to recommended schedule of sputum smear microscopy and quality of registration of patients' medical records, were the 3 variables that significantly predicted treatment success. Diagnostic category was excluded from the model as it did not significantly predict treatment success.

\begin{tabular}{|c|c|c|c|c|c|c|}
\hline \multirow[t]{2}{*}{ Variable } & \multicolumn{2}{|c|}{ Successful } & \multicolumn{2}{|c|}{ Unsuccessful } & \multicolumn{2}{|c|}{ Total } \\
\hline & No. & $\%$ & No. & $\%$ & No. & $\%$ \\
\hline \multicolumn{7}{|l|}{ Sex } \\
\hline Male & 157 & 89.2 & 19 & 10.8 & 176 & 70.7 \\
\hline Female & 65 & 89.0 & 8 & 11.0 & 73 & 29.3 \\
\hline Significance & \multicolumn{6}{|c|}{ Chi-squared test $P=0.970$} \\
\hline \multicolumn{7}{|l|}{ Employment status } \\
\hline Employed & 100 & 92.6 & 8 & 7.4 & 108 & 43.4 \\
\hline Unemployed & 122 & 86.5 & 19 & 13.5 & 141 & 56.6 \\
\hline Significance & \multicolumn{6}{|c|}{ Chi-squared test $P=0.970$} \\
\hline \multicolumn{7}{|l|}{ Diagnostic category ${ }^{a}$} \\
\hline 1 & 129 & 93.5 & 9 & 6.5 & 138 & 56.8 \\
\hline II & 10 & 58.8 & 7 & 41.2 & 17 & 7.0 \\
\hline III & 80 & 90.9 & 8 & 9.1 & 88 & 36.2 \\
\hline Significance & \multicolumn{6}{|c|}{ Monte Carlo test $P<0.001$} \\
\hline \multicolumn{7}{|l|}{ Facility } \\
\hline El-Mamora & 123 & 90.4 & 13 & 9.6 & 136 & 54.6 \\
\hline Bacos & 99 & 87.6 & 14 & 12.4 & 113 & 45.4 \\
\hline Significance & \multicolumn{6}{|c|}{ Chi-squared test $P=0.474$} \\
\hline \multicolumn{7}{|l|}{ Conformity, initial ${ }^{b}$} \\
\hline Conforming & 169 & 90.9 & 17 & 9.1 & 186 & 74.7 \\
\hline Non-conforming & 53 & 84.1 & 10 & 15.9 & 63 & 25.3 \\
\hline Significance & \multicolumn{6}{|c|}{ Chi-squared test $P=0.137$} \\
\hline \multicolumn{7}{|c|}{ Conformity, continuation ${ }^{c}$} \\
\hline Conforming & 206 & 94.5 & 12 & 5.5 & 218 & 87.6 \\
\hline Non-conforming & 16 & 51.6 & 15 & 48.4 & 31 & 12.4 \\
\hline Significance & \multicolumn{6}{|c|}{ Chi-squared test $P<0.001$} \\
\hline Total & 222 & 89.2 & 27 & 10.8 & 249 & 100.0 \\
\hline
\end{tabular}




\begin{tabular}{|c|c|c|c|c|}
\hline Variable & B & $P$-value & $\operatorname{Exp}(B)$ & $95 \% \mathrm{Cl}$ \\
\hline \multicolumn{5}{|l|}{ Initial model } \\
\hline 1 & 3.51 & $<0.001$ & 33.55 & $9.19-122.44$ \\
\hline 2 & 2.64 & $<0.001$ & 13.99 & $3.38-57.97$ \\
\hline 3 & -7.88 & 0.025 & 0.00 & $0.00-0.37$ \\
\hline 4 & -0.08 & 0.784 & 0.93 & $0.53-1.61$ \\
\hline Constant & 4.98 & 0.082 & 145.79 & \\
\hline \multicolumn{5}{|l|}{ Final model } \\
\hline 1 & 3.51 & $<0.001$ & 33.46 & $9.19-121.87$ \\
\hline 2 & 2.67 & $<0.001$ & 14.46 & $3.56-58.77$ \\
\hline 3 & -7.91 & 0.025 & 0.00 & $0.00-0.37$ \\
\hline Constant & 4.85 & 0.086 & 127.62 & \\
\hline
\end{tabular}

\section{Significant at $\mathrm{P}<0.05$.}

Variable $1=$ conformity to DOTS drug regimen during the

continuation phase of therapy.

Variable 2 = conformity to recommended schedule of sputum smear microscopy.

Variable 3 = quality of registration of patients' medical records. Variable 4 = diagnostic categories.

$\mathrm{Cl}=$ confidence interval.

\section{Discussion}

It is - erroneously - thought that TB is a disease of the past, but it is still a leading killer worldwide, and TB control programmes will be needed for at least the next 50 years [7]. Even in a highly developed country such as the United States of America, TB has re-emerged as a serious public health problem $[22,33]$.

In most of the world, more men than women are diagnosed with and die from TB [34]. This finding was supported by this study, where most cases were men. Over $80 \%$ of our patients were in the economically productive age group (15-54 years), a finding consistent with previous research indicating that about $75 \%$ of TB patients in developing countries are in this age group $[26,35]$. Over half our patients were unemployed, but whether TB was the result or the cause of the unemployment cannot be conjectured. It is, however, recognized that $\mathrm{TB}$, a chronic debilitating disease, leads to an average of 3-4 months of work-time deficit, resulting in losses of $20 \%-30 \%$ of annual household income. The relationship between TB and poverty is complex; the disease impoverishes those who suffer from it, and the epidemic is exacerbated by socioeconomic decline [36].

Overall quality of performance of smear microscopy was good for all cases. Smear microscopy is the most efficient way of identifying TB cases and is used to monitor the progress of infectious cases during therapy till confirmation of cure [37]. It was shown that $44.2 \%$ of new smearpositive cases converted to smear-negative as evidenced by the second smear microscopy, and by the third smear only $5.5 \%$ continued to be smear-positive. 
The current study showed that, during the initial phase of therapy, three quarters of the patients were conforming to the DOTS recommended drug regimen. On the other hand, during the continuation phase, it was obvious that seven eighths were conforming to DOTS recommended drug regimen. Conformity may be related to type and number of prescribed drugs or duration of treatment course. Most of the process items were always registered in the TB treatment card. Recording and reporting on a continuous basis are crucial to ensure and improve quality of antituberculosis care [5].

As determined in this study, overall success rate at the 2 chest facilities was $89.2 \%$ but the cure rate $(48.6 \%)$ was considered low since an effective programme successfully treats $\geq 85 \%$ of detected cases $[38,39]$. Adherence to currently recommended DOTS strategy can achieve a cure rate up to $99 \%$ [35]. Nevertheless, as indicated by our results, the solution lies in the adequate management of TB control programmes, a result that is harmonious with other research $[40,41]$. Monitoring and evaluation of TB control programmes are indispensable for demonstrating achievements, recognizing problems and assessing improvement initiatives. In this study, an index for measuring overall quality of care delivered to TB patients was developed and it could be applied in these and other settings as a useful benchmarking tool for continuously improving the quality of implementing DOTS strategy.

The limitations of the present study must be highlighted so as to anticipate and reduce them in future similar studies. They included dependence on the record auditing method alone as a tool for assessing the process and outcome of care. It is well-known that that quality of data recording may be unreliable, imprecise, illegible or even fraudulent. The restriction of the study to 2 settings and a 1 -year record auditing was mandated for purposes of feasibility. The results could, however, be generalizable to the remaining 5 chest facilities in Alexandria, given the similarity between these settings and the fact that the 2 study settings represented about half the overall volume of utilization of antituberculosis care in Alexandria since the year 2000. Further studies are required before presuming our findings would be generalizable to other Egyptian governorates.

\section{Conclusion and recommendations}

TB control is a protracted struggle that will require continued mobilization of technical, medical and managerial resources for a long time to come. The strengths of current TB control programmes in Alexandria included: a standardized recording system; satisfactory conversion rate of sputum smear-positive cases; satisfactory success rate; and low default rate. However, major weaknesses included: modest overall quality regarding performance of smear microscopy and the fact that half the cases received poor quality of care.

This study demonstrated that adherence to a standardized drug regimen and smear microscopy along with proper registration of patients' medical records are significant predicting factors determining the outcome of care. Based on these findings, the following recommendations are proposed.

- Success of antituberculosis therapy could be ensured through strict adherence to all the elements of DOTS strategy, with special emphasis on the 3 variables that significantly predicted treatment success in the present study, i.e. conformity to 
DOTS drug regimen during the continuation phase of therapy, conformity to the recommended schedule of sputum smear microscopy and quality of registration of patients' medical records. It must be completely understood that diagnostic category did not significantly predict treatment success.

- The overall quality index is a comprehensive tool for assessing and improving the overall quality of antituberculosis care delivered in accordance with the DOTS strategy. Quarterly cohort analyses based on this index should be maintained; data should be used at the peripheral level and transferred to intermediate and central levels to be utilized in the national planning and control of TB programmes.

- A standardized system of recording and reporting should be continuously monitored and improved to ensure a cure rate of $\geq 85 \%$ in new smear-positive cases, which is considered a reasonable and consistent benchmark for the proper implementation of the DOTS strategy [42].
- Measures to follow up defaulters (such as a call or visit by a social worker) must be sustained to keep the default rate at zero. Managerial abilities and skills at all organizational levels should be strengthened. In the long run, dependence on consultants to control the programmes will be of no avail. Organizations recognize consultants as foreign bodies to be tolerated for a while, but soon to be rejected by an organizational allergic response.

- The delivery of antituberculosis care through free-of-charge governmental services which maintain a reliable supply of antituberculosis drugs should, therefore, be encouraged. This study confirmed previous findings that strict adherence to standardized DOTS strategy is essential to bring TB under control. Removal of the financial barriers via government subsidy is conducive to bringing about conformity and compliance to the treatment regimen, as illustrated in a recent Chinese study [43].

\section{References}

1. Brown JW. TB: keeping an ancient killer at bay. Medical laboratory observer, 2004, 36(11):8-17.

2. Global tuberculosis control: surveillance, planning, and financing. WHO report 2003. Geneva, World Health Organization, 2003 (WHO/CDS/TB/2003.316).

3. Dye $\mathrm{C}$ et al. Consensus statement: global burden of tuberculosis: estimated incidence, prevalence, and mortality by country. WHO Global Surveillance and Monitoring Project. Journal of the American Medical Association, 1999, 282(7):677-86.

4. Chakraborty AK. Epidemiology of tuberculosis: current status in India. In- dian journal of medical research, 2004, 120(4):248-76.

5. Treatment of tuberculosis: guidelines for national programmes. Geneva, World Health Organization, 2003 (WHO/CDS/ TB/2003.313).

6. Raviglione MC, Pio A. Evolution of WHO policies for tuberculosis control, 19482001. Lancet, 2002, 359(9308):775-80.

7. Frieden T, ed. Toman's Tuberculosis: case detection, treatment, and monitoring, 2nd ed. Geneva, World Health Organization, 2004 (WHO/HTM/TB/2004.334).

8. Global tuberculosis programme. Framework for effective tuberculosis control. 
Geneva, World Health Organization, 1994 (WHO/TB/94.179).

9. Sbarbaro J. What are the advantages of direct observation of treatment? In: Frieden T, ed. Toman's Tuberculosis: case detection, treatment, and monitoring, 2nd ed. Geneva, World Health Organization, 2004:183-4 (WHO/HTM/TB/2004.334).

10. Moore RD et al. Cost-effectiveness of directly observed versus self-administered therapy for tuberculosis. American journal of respiratory and critical care medicine, 1996, 154(4 Pt 1):1013-9.

11. Weis SE et al. The effect of directly observed therapy resistance and relapse in tuberculosis. New England journal of medicine, 1994, 330(17):1179-84.

12. Gninafon M. The antituberculosis programme in Benin. Bulletin of the International Union against Tuberculosis and Lung Disease, 1990, 66(Suppl.):57-8.

13. Dye $C$ et al. Evaluating the impact of tuberculosis control: number of deaths prevented by short-term chemotherapy in China. International journal of epidemio/ogy, 2000, 29(3):558-64.

14. [No authors listed]. Results of directly observed short-course chemotherapy in 112,842 Chinese patients with smearpositive tuberculosis. Lancet, 1996, 347(8998):358-62.

15. Zhang LX, Tu DH, Enarson DA. The impact of directly-observed treatment on the epidemiology of tuberculosis in Beijing. International journal of tuberculosis and lung disease, 2000, 4(10):904-10.

16. Arguello L. Results of the tuberculosis control programme in Nicaragua in 19841989. Bulletin of the International Union against Tuberculosis and Lung Disease, 1990, 66(Suppl.):51-2.

17. Norval PY et al. DOTS in Cambodia: directly observed treatment with shortcourse chemotherapy. International jour- nal of tuberculosis and lung disease, 1998, 2(1):44-51.

18. Nyangulu DS, Nkhoma WN, Salaniponi FM. Factors contributing to successful tuberculosis control in Malawi. Bulletin of the International Union against Tuberculosis and Lung Disease, 1990, 66(Suppl.):45-6.

19. Chum HJ. The Tanzania National Tuberculosis/Leprosy Programme in the face of HIV infection. Bulletin of the International Union against Tuberculosis and Lung Disease, 1990, 66(Suppl.):53-5.

20. Frieden $T$. What are examples of effective tuberculosis control programmes? In: Frieden T, ed. Toman's Tuberculosis: case detection, treatment, and monitoring, 2nd ed. Geneva, World Health Organization, 2004:318-21.

21. Corbett $E L$ et al. The growing burden of tuberculosis: global trends and interactions with the HIV epidemic. Archives of internal medicine, 2003, 163(9):1009-21.

22. China Tuberculosis Control Collaboration. The effect of tuberculosis control in China. Lancet, 2004, 364(9432):417-22.

23. Bruchfeld $\mathrm{J}$ et al. Molecular epidemiology and drug resistance of Mycobacterium tuberculosis isolates from Ethiopian pulmonary tuberculosis patients with and without human immunodeficiency virus infection. Journal of clinical microbiology, 2002, 40(5):1636-43.

24. Frieden T. What are examples of effective tuberculosis control programmes? In: Frieden T, ed. Toman's Tuberculosis: case detection, treatment, and monitoring, 2nd ed. Geneva, World Health Organization, 2004:318-21.

25. Maher D, Raviglione M. Why is a recording and reporting system needed, and what system is recommended? In: Frieden T, ed. Toman's Tuberculosis: case detection, treatment, and monitor- 
ing, 2nd ed. Geneva, World Health Organization, 2004:270-3.

26. Treatment of tuberculosis: guidelines for national programmes, 3rd ed. Geneva, World Health Organization, 2003 (WHO/ CDA/TB/203.313).

27. What is DOTS? A guide to understanding the WHO-recommended TB control strategy known as DOTS. Geneva, World Health Organization, 1999 (WHO/CDS/ CPC/TB/99.270).

28. Global tuberculosis control. WHO report 2001. Geneva, World Health Organization, 2001 (WHO/CDS/TB/2001.287).

29. Espinal M, Frieden T. What are the causes of drug-resistant TB? In: Frieden T, ed. Toman's Tuberculosis: case detection, treatment, and monitoring, 2nd ed. Geneva, World Health Organization, 2004:207-8.

30. Schreuder B et al. Viewpoint: why and how tuberculosis control should be included in health sector reviews. Tropical medicine and international health, 2004, 9(8):910-6.

31. Public-private mix for DOTS: practical tools for implementation. Geneva, World Health Organization, 2003 (WHO/CDS/ TB/2003.325).

32. Bhat $S$ et al. Revised national tuberculosis control programme: an urban experience. Indian journal of tuberculosis, 1998, 45(4):207-10.

33. Davidson BL. A controlled comparison of directly-observed therapy vs self-administration therapy for active tuberculosis in the urban United States. Chest, 1998, 114:1239-43.

34. Tuberculosis and gender. Geneva, World Health Organization, 2005 (http://www. who.int/tb/dots/gender/en/, accessed 5 February 2007).

35. Knight L. Tuberculosis and sustainable development. Geneva, World Health Or- ganization, 2000 (Stop TB Initiative series WHO/CDS/STB/2000.4).

36. Ahlburg D. The economic impact of tuberculosis. Geneva, World Health Organization, 2000 (WHO/CDS/STB/2000.5).

37. Luelmo $F$. What is the role of sputum microscopy in patients attending health facilities? In: Frieden T, ed. Toman's Tuberculosis: case detection, treatment, and monitoring, 2nd ed. Geneva, World Health Organization, 2004:7-10.

38. Raviglione M, Frieden T. What are examples of effective tuberculosis control programmes? In: Frieden T, ed. Toman's Tuberculosis: case detection, treatment, and monitoring, 2nd ed. Geneva, World Health Organization, 2004:318-21

39. Smith I. What are the global targets for tuberculosis control and what are the basis for these targets? In: Frieden T, ed. Toman's Tuberculosis: case detection, treatment, and monitoring, 2nd ed. Geneva, World Health Organization, 2004:226-9.

40. Fox W. General considerations on the choice and control of chemotherapy in pulmonary tuberculosis. Bulletin of the international journal of tuberculosis and lung disease, 1972, 47:51-71.

41. Toman K. What are the keys to cure? In: Frieden T, ed. Toman's Tuberculosis: case detection, treatment, and monitoring, 2nd ed. Geneva, World Health Organization, 2004:260-3.

42. Luelmo F, Frieden T. What are the indicators of an effective tuberculosis control programme? In: Frieden T, ed. Toman's tuberculosis: case detection, treatment and monitoring - questions and answers, 2nd ed. Geneva, World Health Organization, 2004:315-6 (WHO/HTM/ TB/2004.334).

43. Xu B et al. DOTS in China-removing barriers or moving barriers? Health policy and planning, 2006, 21(5):365-72. 